\title{
DOCUMENTO
}

\author{
Exposición del Embajador de Chile en el \\ Perú, don Carlos Martínez Sotomayor, en el \\ IV Congreso de la Asociación Chilena de \\ Ciencia Política, Valparaíso, 3 y 4 de octubre \\ de 1996.
}

En el marco de la globalización, los cambios experimentados en el sistema internacional y, en consecuencia los nuevos principios y desafios que han surgido, se describen las bases del proceso de transición que se ha llevado a cabo en América Latina. Este proceso, según el autor, le ha permitido consolidarse como un actor intemacional que puede proyectarse al mundo del próximo siglo como un bloque. Desde esta perspectiva, se refiere a la relación bilateral chileno-penuana que ha incorporado nuevos factores a los vínculos tradicionales políticos y diplomáticos, ayudando a ambos países a superar los distanciamientos que han existido históricamente.

\section{La comunidad internacional.}

Desde la óptica de un "nuevo contexto de vecindad latinoamericana", tal vecindad se inserta en un mundo globalizado y cada vez más interdependiente, en cuyo sistema internacional se pueden verificar en las últimas décadas profundas transformaciones en la evolución ya histórica de los esquemas políticos en los que los diversos actores del escenario internacional situaron su influencia y potencialidades de todo orden. En el que las concepciones ideológicas y la consiguiente "lucha por el poder" perfilaron un quehacer enmarcado en bloques multinacionales excluyentes en si mismos que nos llevaron por una peligrosa senda de conflictos políticos y bélicos en todo el orbe.

Empero la caída de las fronteras ideológicas impuestas por la Guerra Fría generó expectativas de una era de paz y seguridad global, que se vieron reforzadas por la expansión de la democracia y el surgimiento de una nueva conciencia sobre la importancia de la promoción y defensa de los Derechos Humanos en el mundo. Al tiempo, los procesos de globa- 
lización e interdependencia económica fueron originando otras alternativas de progreso, propiciando nuevas modalidades de difusión y transferencia de tecnología y conocimiento. Cosmovișión que busca enriquecer la tradicional concepción del progreso -entendido esencialmente sólo como un objetivo de mayor bienestar económico y materialcon una nueva mirada tendiente a la consecución del desarrollo integral de los pueblos -en el que los principios sustentados en el derecho natural y en el humanismo propenden a reencontrarse de manera efectiva en las metas por alcanzar, tanto colectiva como unilateralmente por las naciones-.

En ese contexto, en el sistema internacional, surgen o se reafirman principios y valores identificados en la búsqueda de soluciones para erradicar la extrema pobreza, la desigualdad entre individuos y entre los Estados, la degradación del medio ambiente, el desempleo y el analfabetismo, la migración desorganizada, la discriminación contra mujeres y jóvenes, entre otros. Nuevos desafios éstos, que hoy también se constituyen en factores de conflicto tanto o más importantes que la proliferación militar o la confrontación ideológica. Enfrentarlos requiere desplegar la imaginación, la creatividad y la solidaridad de la comunidad internacional, así como disponer de recursos tanto o más cuantiosos que los que se emplean hoy en combatir o resolver conflictos ya iniciados.

No obstante, junto a los signos de esperanza también se advierten el resurgimiento o la existencia latente de nuevos conflictos de indole económica, política, étnica, religiosa y cultural, y una tendencia hacia la fragmentación y la diferenciación, que presentan potenciales amenazadas a la paz y nuevos desafios para el orden intemacional, como bien lo señalara en su oportunidad el señor Ministro de Relaciones Exteriores de Chile en la Asamblea General de Naciones Unidas

\section{Latinoamérica}

En este-proceso de transición, América Latina no ha estado ausente. En efecto, no sólo ha sido receptora de las mutaciones del sistema internacional sino que, además, ha contribuido a una positiva evolución de las mismas, a través de una participación activa en los esfuerzos que se llevan a cabo para preservar la paz y la seguridad mundial, partiendo por transformar al interior de sus fronteras hemisféricas los esquemas de poder e influencia política y económica que hasta hace poco imperaron en su interrelación y en el fuero reservado de cada una de las naciones que la conforman. 
En ese devenir, América Latina ha consolidado en los últimos ạños la democracia como sistema de gobierno, logrando una importante estabilidad política. Asimismo, ha optado por una política económica abierta de fomento al comercio y a la inversión extranjera; ha propendido a consolidar diversos esquemas de cooperación e integración, tanto mediante las vertientes bilaterales como multilaterales.

Lo anterior muestra las columnas en las que se han asentado las bases para conducir el proceso de transformación hemisférica desde un escenario de conflictos a un panorama de afianzamiento de sus instituciones; de respeto a los valores y derechos ciudadanos; de una mayor madurez cívica; de una mayor interrelación entre los Estados; de más conciencia respecto a temas como el desarme, el medio ambiente, la utilización y explotación de sus recursos naturales; de una responsabilidad colectiva respecto al peligro del narcotráfico y el terrorismo; de un conocimiento más acabado de nuestras potencialidades frente a un mundo cada vez más globalizado. En resumen, América Latina empieza a ser un actor en la política mundial observado como un fenómeno donde se ha impuesto la cordura y la sensatez y que bien puede acceder al nuevo siglo como un importante bloque de poder político y económico en el escenario mundial.

Se ha desarrollado una vecindad latinoamericana que se esfuerza por consolidar la integración regional sobre la base de una concepción de regionalismo abierto. Un regionalismo no excluyente del mundo sino complementario del mismo y positivamente vinculado con otros esquemas de influencia y poder que se verifican o se gestan actualmente en el nuevo orden internacional. Una vecindad en la que la preservación de la estabilidad democrática, la concertación política, la consolidación de sistemas económicos nacionales que propendan al desarrollo sostenido y sustentable, la solución a los diferendos históricos, la erradicación de la extrema pobreza y de las sombras de la corrupción, la solución pacífica de las controversias, la cooperación e intercambio científico y tecinológico, la lucha contra el narcotráfico y el terrorismo, constituyen los principios y objetivos prioritarios de la política exterior de nuestros pueblos, en particular, y de Latinoamérica, en general.

Por ello, y consecuente con lo anterior, Chile concordó en la definición de las tres grandes áreas que se perfilaron como temas fundamentales de la Cumbre de las Américas, celebrada en Miami en 1995, a saber: el fortalecimiento de la democracia como un principio rector de nuestras sociedades; la facilitación de los flujos comerciales y de inversión en el 
hemisferio, con-miras a una efectiva integración económica; y la búsqueda de la prosperidad compartida en un marco de desarrollo sustentable.

En esa perspectiva, y a modo de ejemplo, dada mi calidad de Embajador de Chile en Perú, me referiré a la relación bilateral chileno-peruana.

\section{Relación Chile-Perú.}

1. Esta ha sido una vinculación que ha cambiado en forma considerable pasando rápidamente de los tradicionales vinculos políticos y diplomáticos -en varios periodos débiles y a veces traumáticos-a una relación más universal, de escenarios múltiples, enriquecida por los factores económicos, comerciales, financieros, de los transportes y del turismo.

Lo cultural, los intercambios acadẹmicos y los vínculos castrenses entre las instituciones de la defensa nacional de ambos paises, también se han acrecentado alcanzando niveles de excelencia.

2. La relación entre Perú y Chile se ha constituido así, en los últimos años, en una de las relaciones más completas y de acelerada integración que exhibe Chile en América Latina.

A modo de ejemplo, las inversiones chilenas en Perú son superiores a los 2.000 millones de dólares; el comercio bilateral alcanzará a 700 millones en 1996. El número de turistas peruanos que visitaron Chile en 1995 fue de 182.000 .

En el campo educacional y cultural se ha propendido a un mayor y mejor nivel de conocimiento recíproco de nuestro patrimonio, junto con propiciar entre ambos paises nuevas fuentes de intercambio y cooperación académica y de transferencia de tecnologías, así como la consolidación de las ya existentes.

3. Este nuevo escenario de la relación bilateral presenta además otras características y potencialidades vinculantes entre Chile y Perú, a saber:

- Su propia universalización.

- Activa y estimulante participación del sector privado y de los empresarios en este proceso.

- Mayores potencialidades de integración y desarrollo de las zonas fronterizas entre el Norte de Chile, Bolivia y el Sur del Perú.

- Desarrollo conjunto de una estrategia hacia el Asia-Pacífico.

- Actividades comunes y posibilidades de proyectos conjuntos en materia de corredores bioceánicos. 
- Perspectivas reales para la mayor utilización y vida de los puertos chilenos del Norte (Iquique, Arica, Antofagasta) y del Sur del Perú (Ilo, Matarani).

- Iniciativas conjuntas en la Antártica con un rol activo de colaboración de parte de Chile, en áreas de ciencia e investigación.

- Medidas de confianza mutua entre las Fuerzas Armadas de Chile y Perú.

- Formas múltiples de cooperación de transferencia tecnológıca, especialmente de parte de Chile a Perú.

4. Esta nueva escenografia y las actuales dimensiones de la relación entre Perú y Chile, invitan lógicamente a ubicar el tema de las cláusulas pendientes del Tratado de 1929 en su verdadera y real categoría y nivel. Antes era prácticamente "el" tema de la relación. Hoy es "uno" de los temas y, para muchos, no el principal.

Hasta 1993 si había desentendimientos políticos a propósito de esta materia se deterioraba todo el vínculo bilateral. Hoy, si esto ocurriera, sería solamente uno de los variados y múltiples aspectos de la relación entre Chile y Perú.

5. Es evidente que todavía no se superan las distancias y suspicacias, consecuencia de tradiciones, atavismos y de una historia de conflictos entre ambos países. Hay que trabajar incansablemente en base a que tales desconfianzas e inconvenientes existen, pero con la certeza ahora, en 1996, de que también se han incorporado a la relación bilateral otros factores y todos muy positivos. 